\title{
A DIMENSÃO POLÍTICA DO TRABALHO: A COOPERAÇ̃̃O COMO FERRAMENTA DE GESTÃO DA SOCIEDADE
} LA DIMENSIÓN POLÍTICA DE TRABAJO: LA COOPERACIÓN COMO HERRAMIENTA DE GESTIÓN DE LA SOCIEDADE THE POLITICAL DIMENSION OF WORK: COOPERATION AS SOCIETY MANAGEMENT TOOL

http://dx.doi.org/10.1590/1807-0310/2018v30164500

Paulo César Zambroni-de-Souza e Anísio José da Silva Araújo Universidade Federal da Paraíba, João Pessoa/PB, Brasil

João de Deus Gomes da Silva Société Française et Francophone d'Etique Médicale, Paris, France

\section{Resenha de}

Dejours, C. (2015). Le choix, souffrir au travail $n$ 'est pas une fatalité. Montrouge, Fr: Bayard.

Em 2015, Christophe Dejours publicou na França o livro Le choix: souffrir au travail n'est pas une fatalité (A escolha: sofrer no trabalho não é uma fatalidade), no qual o trabalho é discutido em sua dimensão política.

$\mathrm{O}$ autor é fundador da abordagem denominada Psicodinâmica do Trabalho (PDT) e professor titular da "Cátedra Psicanálise-Saúde-Trabalho", no Conservatoire National des Arts et Métiers (CNAM Paris). Tem vários livros publicados no Brasil, tendo sido o primeiro A loucura do trabalho: estudo de Psicopatologia do Trabalho (1987) e o mais recente Trabalho vivo (Tomos I e II) (2012).

Sobre o título, seguindo o autor, é necessário fazer dois esclarecimentos. $\mathrm{O}$ primeiro deles é em relação ao termo "sofrer". O autor esclarece que "este sofrimento deve ser entendido no sentido estrito do sofrimento patogênico" (p. 7), ou seja, aquele que tende a levar o sujeito ao adoecimento.

A outra questão sobre o título diz respeito ao referido sofrimento não ser uma fatalidade. Essa proposição vem se opor àquela proposta por Margaret Tatcher em 1997: "There is no alternative" (não há alternativa). O livro defende, a partir de exemplos de intervenções e discussões teóricas, que há alternativa ao modelo neoliberal, que acirra cada vez mais a competitividade entre as pessoas e destrói a cooperação fundamental para manutenção dos coletivos. A dimensão política do trabalho, aspecto que perpassa todo o livro, já estava presente na obra do autor, por exemplo, em A banalização da injustiça social (2007) ou em Trabalho vivo (2012), mas nesse novo livro, ele aprofunda tal dimensão e propõe um modelo de governança de empresa que leva em conta cinco registros: a qualidade do serviço; a produtividade; os impactos externos (inclusive sobre as relações sociais e o meio ambiente); os efeitos de reflexividade da produção sobre os recursos materiais; a rentabilidade. Desta forma, a proposta é que a rentabilidade deixe de ser soberana nas escolhas da gestão das empresas e, sim, seja levada em conta juntamente com as outras dimensões. A obra defende que para compreender a dimensão política da organização do trabalho e produzir transformações positivas é necessário investigar e conhecer profundamente o trabalho vivo em dois níveis: individual (a engenhosidade) e coletivo (a cooperação). Assim, esse livro vai ao encontro daqueles que, seguindo a tradição de Lane (1989), entendem que o profissional de Psicologia deve ser um "agente de transformação da sociedade" (p. 7).

O livro é dividido em duas partes. Na parte $\mathrm{I}$ - O tempo da resignação: tristes derivas no mundo do trabalho, com os capítulos: A normalização do cuidado: o trabalho em um serviço de reanimação; Prestar serviço ou vender serviço? O trabalho em um centro de chamadas telefônicas. Na parte II - O tempo de mudança: para um modelo econômico sob o critério do trabalho vivo", há os capítulos: Trabalhar de outro modo, é possível; Os novos administradores; Uma revolução econômica: novas modalidades de criação do valor.

Com relação a esse último capítulo, há um erro de edição, já que na página 187 o subtítulo se apresenta como "Um tournant économique" (Uma mudança de rumo econômico), enquanto que no sumário (p. 238) aparece "Une révolution économique" (Uma revolução econômica).

$\mathrm{Na}$ parte I, o autor desenvolve suas reflexões a partir de pesquisas realizadas por sua equipe, contando com a contribuição de Christophe Demaegdt, Isabelle Gernet, Stéphane Le Lay, Duarte Rolo e Florence Spira Chekroun. Cabe lembrar que a pesquisa em 
psicodinâmica do trabalho se define como uma "pesquisa-ação" (Dejours, 2004a, p. 114), ou seja, uma pesquisa com intenção declarada de produzir transformações na organização do trabalho, mostrando a herança que a PDT recebe da Ergonomia (Dejours, 2006). A parte II é escrita em coautoria com Christian du Tertre, que é professor em Ciências Econômicas na Universidade Paris Diderot, diretor científico do Laboratório de Intervenção e de Pesquisa ATEMIS (Análise do Trabalho e das Mutações das Indústrias e de Serviços) e diretor científico do grupo "Economia da Funcionalidade e Desenvolvimento Durável".

As pesquisas que são tomadas como pontos de partida para as discussões presentes no livro foram realizadas em diferentes setores: (a) um centro de reanimação de um hospital público, (b) em um centro de tele-atendimento e (c) uma empresa de desenvolvimento urbano. Interessante notar que neste último caso, há um aspecto novo na formulação da demanda que difere do modelo canônico defendido na metodologia proposta pela PDT (Dejours, 1988). Tal proposta, cujo texto está disponível no Brasil em duas publicações (Dejours, 1987, 2004a), permanece como a referência metodológica dessa abordagem. Ali, o autor afirma que "uma solicitação só pode ser considerada se for proveniente dos próprios trabalhadores" (Dejours, 1987, p. 141). Já na pesquisa na empresa de desenvolvimento urbano, a demanda foi feita não pelos trabalhadores mas pela direção, "mais exatamente por seu diretor de recursos humanos" (Dejours, 2015, p. 113). É certo que, neste caso, como a leitura do texto demonstra, havia um grande sofrimento das pessoas que ocupavam cargos de direção nesta empresa e é com eles que a pesquisa teve seu ponto de partida.

Quanto à parte I do livro, apresentada em três capítulos, o primeiro deles, "A normalização do cuidado: o trabalho em um serviço de reanimação", trata do caso do trabalho em um hospital, no setor de reanimação, que sofre transformações em sua gestão a partir da introdução do "New Public Management" (p. 27) (Nova Gestão Pública), mediante a qual os resultados são avaliados por meio do retorno financeiro, o que pressupõe que todos os procedimentos sejam monetarizados. Esta forma de administração inviabiliza a gestão dos inúmeros imprevistos que ocorrem no setor e que levam tempo para serem superados, pelo fato de que grande parte da equipe (sobretudo os médicos) consome seu tempo no cumprimento de protocolos e no lançamento dos dados no sistema, muitas vezes acabando por nem conhecer suficientemente os pacientes. Tentar seguir restritamente as normas dos protocolos tem como grave consequência uma precarização da clínica de reanimação pela redução da autonomia dos médicos. Além disso, para que não sofram sanções, cada um acaba ficando "em seu canto" (p. 30), isolado, preocupado em atingir as metas esperadas, dificultando a construção de uma referência partilhada sobre o trabalho, favorecendo o enfraquecimento do coletivo e deixando cada um à própria sorte. Para o autor, abordar o caso deste serviço tem a função de servir como uma "lupa das mutações que afetam a relação subjetiva com o trabalho nas organizações contemporâneas" (p. 46).

O capítulo 2, "Prestar serviço ou vender serviço? O trabalho em um centro de chamadas telefônicas", trata de uma pesquisa em um centro de teleatendimento que o autor define como o "reino da performance" (p. 49). Cabe lembrar que o interesse pelo trabalho de pessoas ligadas à telefonia já estava presente desde o início da Psicopatologia do Trabalho, da qual a PDT é herdeira, como mostra o texto "A neurose das telefonistas" (Le Guillant, Roelens, Bégoin, Béquart, Hamsen, \& Lebreton, 2006). Dejours mostra que tal performance relacionada à venda de serviços é mantida à custa de utilização de ferramentas que geram ansiedade e acabam acarretando muitos pedidos de demissão: avaliações individuais, quantitativas; estímulo à competição entre os trabalhadores. Também ali há uma destruição dos coletivos, já que "a animosidade, a concorrência e o ressentimento se instalam no seio da equipe, tornando o trabalho coletivo e a cooperação difíceis, ou impossíveis" (p. 52). Trabalhar naquele meio supõe também lidar com o sofrimento ético, já que muitas vezes os operadores se veem forçados a enganar os clientes para atingir as metas. Suportar tal sofrimento requer muitas manobras psíquicas, tais como cair no cinismo, como abordado no capítulo seguinte.

No capítulo 3, "O cinismo da resignação", o autor afirma que o cinismo, encontrado outrora junto a certos dirigentes (Dejours, 2007), ganha terreno e chega aos trabalhadores, produzindo mais cinismo que acaba, em alguns sujeitos, tomando a forma de amargura, resignação e falta de vontade de responder politicamente. Além disso, gera a sensação de trair os clientes e a si mesmo, levando muitas vezes a quadros de descompensação psíquica e somática, à desolação e até ao suicídio. Neste quadro, o cada um por si corrói a personalidade, o sentido do trabalho, o sentido comum de justiça e desmoraliza as equipes. Na falta do coletivo, cada um tem que lidar sozinho com as exigências que o trabalho e sua organização trazem. Para o autor, seguindo o que está presente desde o início da sua obra e que se apresenta de maneira mais detalhada em alguns de seus livros, como Le corps d'abord (Dejours, 2001) e Psychopathologie du 
travail (Dejours \& Gernet, 2012), para compreender esse fenômeno é necessário valer-se da Psicanálise, ao mesmo tempo em que esses problemas requisitam certos aprofundamentos "metapsicológicos deixados em suspense pelos textos de Freud" (Dejours, 2015, p. 95), embora neste livro Dejours não tenha tido espaço para entrar nessas questões, como pôde fazê-lo em outros (por exemplo Trabalho vivo, Tomo II).

A parte II, subdividida em três capítulos, iniciase com uma pergunta, cuja resposta afirmativa é a tese defendida pelo livro, a saber: "reformando a organização do trabalho e a administração da empresa pode-se fazer advir uma nova maneira de fazer sociedade e de governar?" (p. 105). A condição para que a resposta seja "sim" é partir do trabalho real e fornecer reconhecimento ao que cada um oferece à construção da obra em comum, instituindo diversas formas de cooperação que se estenderão para além dos muros da empresa.

No capítulo 1 desta parte II, "Trabalhar de outro modo, é possível", ao descrever a enquete conduzida junto a uma empresa de desenvolvimento urbano, o livro expõe os princípios que orientam a intervenção em PDT, a saber: a importância do trabalho efetivo ${ }^{1}$ e do trabalho coletivo. Além disso, descreve detalhes de várias etapas da enquete, de tal forma que, apesar deste não pretender ser um texto metodológico, ele se junta a outros que também acabam por trazer discussões que dizem respeito ao tema do método (Dejours, 2004b; Dejours \& Bègue, 2010; Dejours \& Jayet, 1994), mesmo que não seja o texto clássico da PDT sobre o tema, já citado (Dejours, 1987, 1988, 2004a).

Nessa enquete, assim como nas anteriores, tratase de repensar a organização do trabalho de tal modo que "ofereça melhores condições de possibilidade ao florescimento individual e à cooperação" (p. 122), consistindo em "despersonalizar os problemas e restaurando a confiança" (p. 133). Na empresa em questão, havia uma grande perda da confiança, acompanhada de solidão e sofrimento. A desconfiança era tanta que foi necessário, em um determinado momento, utilizar entrevistas individuais, algo que não é canônico na metodologia da PDT (Dejours, 1987, 1988), embora já tivesse sido utilizada anteriormente (Dejours \& Bègue, 2010; Dejours \& Jayet, 1994).

A fim de restabelecer a confiança e valorizar o trabalho vivo, a direção exerce um forte papel, como discutido no capítulo seguinte.

No capítulo 2 desta parte II, "Os novos administradores", os autores defendem que cabe aos gestores valorizar a inteligência no trabalho e reconhecê-la, caso contrário ela "gera certamente sofrimento nos trabalhadores e destruição de valor" (p. 167), o que vai contra o objetivo principal da gerência, que é gerar valor para a organização. Reconhecer esta inteligência passa por aceitar e dar visibilidade às dificuldades que cada um encontra na realização de um ato técnico, assim como é necessário que se permitam e se criem espaços de deliberação baseada na troca de experiências, além de espaços de desenvolvimento e avaliação da cooperação. Desta forma, o texto defende que a gerência tem as funções de: "Fornecer uma assistência profissional a seus subordinados" (p. 170); "Cultivar a confiança por sua capacidade de escutar seus subordinados, não apenas individualmente, mas sobretudo coletivamente" (p. 172); "Coordenar as inteligências para obter sua harmonização e mesmo sua sinergia e suscitar a cooperação" (p. 175); "Cultivar espaços de deliberação entre membros da equipe, segundo duas dinâmicas: um espaço formal de discussão, um espaço informal que se localiza nos espaços de convivialidade" (p. 176); "Retransmitir para baixo as diretrizes da empresa, assumindo a interpretação que ele faz para os serviços que ele dirige" (p. 178); "Quando constata repetidos fracassos de seus subordinados, ele tem por missão recolocar em discussão a doutrina" (p. 179), ou seja, a maneira como se pretende que se pense e se direcione as ações na empresa; "A coragem de assumir suas decisões, não se contentar em transmitir as ordens que vêm do alto, se desresponsabilizando pelo que elas implicam para seus subordinados" (p. 183); "A participação na elaboração da doutrina da empresa frente à cidade" (p. 184).

Seguindo este último item, o livro defende que a empresa precisa, de fato, assumir um lugar na sociedade, pois pode renovar o viver juntos ou destruílo, não somente dentro de seus muros, mas também em seu exterior. Poderá permitir, assim, "conjurar a violência no tratamento dos conflitos entre os seres humanos" (p. 185), dentro da empresa, espalhando-se para fora dela.

No capítulo 3 desta parte II, "Uma revolução econômica: novas modalidades de criação do valor", o livro reforça a relação entre o que se faz no seio de uma organização e a sociedade, o que passa por um elemento que é central para a PDT, a saber, a cooperação, que se dá em três níveis: em uma equipe (cooperação horizontal), na hierarquia (cooperação vertical) e a que se estende às pessoas exteriores à empresa (cooperação transversal). Aqui ganha força a noção de serviço (mesmo que não restrita ao setor de serviços, na medida em que o fornecimento de um bem produzido na agricultura ou na indústria gera transformações no usuário, ou seja, presta um serviço), na qual o trabalhador que oferece o produto ou o serviço 
mantém uma relação com o beneficiário, o que requer de ambos uma ligação que se dá em cinco níveis: psíquica; comunicacional; técnica; social; jurídica. Desta forma, a subjetividade, que vai se expressar na relação do trabalhador com seu produto ou seu cliente, além da relação com seus pares, coloca em jogo sua saúde mental, mas também a sobrevivência econômica da empresa, que depende da aceitação de seu produto ou serviço para que possa crescer.

Trata-se de uma "passagem da era industrial para a era de serviço" (p. 202), que requer indubitavelmente a subjetividade. Assim, a gestão precisa respeitar a subjetividade, que, para ser conjugada com a performance, deve valorizar: a qualidade do serviço; a produtividade; os impactos externos (positivos ou negativos) da empresa; a rentabilidade ou equilíbrio orçamentário.

Essa proposição de valorização da subjetividade (que é impossível estar ausente do trabalho, ainda que negada) vem se opor a um movimento de financeirização das empresas que se tornou poderoso a partir dos anos 90 , no qual a rentabilidade tornou-se o registro primeiro, mesmo que desligado da produtividade, fazendo fechar muitas plantas industriais, favorecendo a concentração e o deslocamento da produção. Como efeito, gerou-se muito desespero, desemprego, precarização, explosão da violência na vida social. O livro defende que "há alternativa" (p. 217) e que contra tal movimento atualmente sãos vistas resistências, sobretudo em empresas menos ligadas aos mercados financeiros, muitas vezes pequenas e médias, que "já questionam uma financeirização que eles julgam excessiva" (p. 188).

Por fim, Dejours conclui o livro afirmando que a prevenção das patologias mentais no trabalho está ligada à recomposição da cooperação em seus três níveis, passando pela transformação na organização do trabalho para valorizar o trabalho vivo. Ao lado disto, a criação de espaços de deliberação na empresa deve ser uma prática do exercício democrático que ligam trabalho e sociedade, pois "os laços entre saúde mental no trabalho e cooperação são a réplica, em nível do indivíduo, dos laços entre organização do trabalho e governo, em nível da cidade" (p. 212). A oposição a isto é a avaliação individualizada, que destrói a cooperação e progressivamente arruína a democracia a partir do interior da empresa.

Neste sentido, esse texto assume que, atualmente, as condições histórico-sociais de que fala Lane (1989, p. 19) são favoráveis ao desenvolvimento do individualismo, sendo a cooperação no trabalho uma chave para a produção de uma sociedade democrática. Por isso, conclui-se esta resenha convidando os leitores de Psicologia \& Sociedade a ler o livro, ao mesmo tempo em que se torce por sua tradução no Brasil!

\section{Nota}

1 Aqui os autores usam trabalho efetivo (effectif) e não real (réel), como é comum encontrar em outros textos, sobretudo da Ergonomia.

\section{Referências}

Dejours, C. (1987). A loucura do trabalho: estudo de psicopatologia do trabalho. São Paulo: Cortez; Oboré.

Dejours, C. (Dir.). (1988). Plaisir et souffrance dans le travail. Paris: Edition de l'AOCIP.

Dejours, C. (2001). Le corps, d'abord. Paris: Payot \& Rivages.

Dejours, C. (2004a). A metodologia em psicopatologia do trabalho. In S. Lancman \& L. I. Sznelwar (Orgs.), Christophe Dejours: da psicopatologia à psicodinâmica do trabalho (pp. 105-126). Rio de Janeiro: Fiocruz; Brasília, DF: Paralelo 15.

Dejours, C. (2004b). Addendum: da psicopatologia à psicodinâmica do trabalho. In S. Lancman \& L. I. Sznelwar (Orgs.), Christophe Dejours: da psicopatologia à psicodinâmica do trabalho (pp. 47-104). Rio de Janeiro: Fiocruz; Brasília, DF Paralelo 15.

Dejours, C. (2006). Sciences du travail et politique. À partir de l'œuvre de Wisner, Travailler, 1(15), 207-218.

Dejours, C. (2007). A banalização da injustiça social. Rio de Janeiro: FGV.

Dejours, C. (2012). Trabalho vivo (Tomos I, II). Brasília, DF: Paralelo 15

Dejours, C. (2015). Le choix, souffrir au travail n'est pas une fatalité. Paris: Bayard.

Dejours, C. \& Bègue, F. (2010). Suicídio e trabalho: o que fazer? Brasília, DF: Paralelo 15.

Dejours, C. \& Gernet, I. (2012). Psychopathologie du travail. Issy-les-Moulineaux, Paris: Editeur Elsevier Mason.

Dejours, C. \& Jayet, C. (1994). Psicopatologia do trabalho e organização real do trabalho em uma indústria de processo: metodologia aplicada a um caso. In C. Dejours, E. Abdoucheli \& C. Jayet (Eds.), Psicodinâmica do Trabalho (pp. 67-118). São Paulo: Atlas.

Lane, S. T. M. (1989). Apresentação. In S. T. M. Lane \& W. Codo (Orgs.), Psicologia Social: o homem em movimento $\left(8^{\mathrm{a}}\right.$ ed., pp. 7-9). São Paulo: Atlas.

Le Guillant, L., Roelens, R., Begoin, J., Béquart, P., Hansen, M., \& Lebreton, F. (2006). A neurose das telefonistas. In M. E. A. Lima (Org.), Escritos de Louis Le Guillant: da ergoterapia à psicopatologia do trabalho (pp. 175-188). Petrópolis, RJ: Vozes.

Submissão em: 27/05/2016

Revisão em: 22/04/2017

Aceite em: 28/04/2018

Agências de fomento: Conselho Nacional de Desenvolvimento Científico e Tecnológico [CNPq]. Processo no 302861/2015-7. 
Paulo César Zambroni-de-Souza é doutor em Psicologia

Social, docente do Programa de Pós-graduação em

Psicologia Social da Universidade Federal da Paraíba.

Bolsista de Produtividade em Pesquisa do Conselho

Nacional de Desenvolvimento Científico e Tecnológico

[CNPq].

Endereço para correspondência: Departamento de

Psicologia - Universidade Federal da Paraíba. Cidade

Universitária, s/n ${ }^{\circ}$. Bairro Castelo Branco. João Pessoa/PB,

Brasil. CEP 58051-900.

E-mail: paulozamsouza@yahoo.com.br

Anísio José da Silva Araújo é doutor em Saúde Pública, docente do Programa de Pós-graduação em Psicologia social da Universidade Federal da Paraíba.

E-mail: anisiojsa@uol.com.br

João de Deus Gomes da Silva é doutor em Saúde Coletiva, membro da equipe de pesquisa EA 4056 Psychologie clinique, psychopathologie, psychanalyse, Université Paris Descartes - Sorbonne Paris Cité, France.

E-mail: jdeusgomes@gmail.com 